\title{
UN OLVIDADO JARDÍN DE IA CATEDRAL DE MÉXICO
}

\author{
ELISA GARCÍA BARRAGÁN
}

Manuel Toussaint, en su devoto quehacer de historiador y crítico de arte, manifestó un especial interés por la Catedral de la Ciudad de México, poco escapó a su erudito saber en sus estudios sobre tan magnífico templo. Por lo tanto considero pertinente, en este su homenaje, traer a cuento las noticias que en torno a la creación de un jardín en el atrio de la Catedral publicara a fines de $1880, \mathrm{La}$ Voz de México, diario político, religioso y científico. En su pormenorizada información este periódico no sólo se refiere a tan importante mejora urbana, insiste además en la necesidad de devolverle su prístina apariencia a la fachada de esa iglesia.

La Voz de México para justificar su pertinencia en ese asunto y como un recordatorio se ocupa de la génesis, proceso constructivo y de las tierras que guarda nuestra Catedral, publicando los días 20, 21, 22, 25 y 26 de octubre de ese año, parte de la célebre crónica del Dr. D. Isidro Sariñana: Noticia breve de la solemne deseada, última dedicación del Templo Metropolitano de México, editada, en 1668. Texto ahora inaccesible y del que Toussaint dice:

... ha sido copiada en su parte histórica por todos aquellos que hemos escrito después acerca del gran monumento. Como detalle curioso, si que lamentable a causa de una mala lectura de su texto, debida a un punto y seguido que debió ser una coma, se ha repetido mil veces el error de que los cimientos del edificio itardaron en ser construidos cuarenta y dos años!

Las informaciones de Sariñana son exactas en todo, leyendo correctamente su párrafo mal interpretado, y sólo podemos reprocharle su parquedad en lo que se refiere a la catedral vieja, al verdadero comienzo de la nueva y a otros detalles. Dada la rareza del libro, sería de desearse una reimpresión. ${ }^{1}$

Atendiendo a lo indicado por don Manuel Toussaint y mientras la esperada reedición aparece, creo conveniente incluir como apéndice en el

\footnotetext{
${ }^{1}$ Manuel Toussaint La Catedral de México y el Sagrario Metropolitano, su tesoro, su arte, México, Editorial Porrúa, 2a ed, 1973, pp. XXIV, XXV.
} 
presente trabajo, los escritos tomados de la obra de Sariñana y dados a conocer, más dos artículos en el mismo periódico, acerca de la construcción del jardín, en los que se trata de los gastos de esa obra así como la generosa respuesta de la ciudadanía para llevar a cabo tal ornato.

En 1840, con la finalidad de hacer más cómodo y atractivo el célebre "Paseo de las Cadenas", en la acera de Catedral se plantaron fresnos colocándolos al hilo con "cinco varas de amplitud", (más o menos cada cinco metros). La anterior medida desagradó a buena parte de la población pues se esgrimía el argumento de que los árboles taparían la fachada del templo. Poco tiempo después, el Ayuntamiento trasladó los árboles a la Alameda Central; sin embargo en 1847 se volvieron a plantar fresnos en el perímetro catedralicio y se ampliaron las banquetas.

Para 1849 ignoto viajero deja constancia de la imagen de esa parte de la capital al relatar:

La plaza mayor, formada de la majestuosa Catedral, el Palacio de gobierno la portalería... presenta por su extensión y por los edificios que la rodean, el aspecto más sorprendente y más bello que pueda imaginarse. Hace pocos años se plantaron unos arbolitos delante del atrio de la Catedral, y aunque es verdad, que quitan un poco la vista a la hermosa fachada, por otra parte, lo frondoso de sus copas de un verde brillante, le dan cierto aire de alegría y con esto se ha formado además un agradable paseo, muy concurrido en las noches de luna. ${ }^{2}$

Tan ideal fisonomía desaparece pocos años después y así el hermoso "Paseo de las Cadenas", perdía su atractivo ya que el panteón que se encontraba en el atrio de Catedral, se había convertido en un inmundo basurero. En septiembre de 1881 el entonces Regidor de Paseos, Eugenio Barreiro propuso quitar las cadenas y "extender el jardín de la plaza hasta el atrio alto de Catedral", transformando el terreno comprendido entre esa antigua demarcación y el monumento, en jardines limpios y cuidados. Tal iniciativa fue aceptada con júbilo por los citadinos, y ya para septiembre de 1891, La Voz de México empezó a notificar los avances en la realización del jardín; por medio de comunicaciones tanto en su sección de "Miscelánea" como en su "Revista Semanal".

Previamente al inicio del jardín, el periódico, el 10 de agosto de 1881 inscribió en su "Miscelánea" un remitido de El Diario:

Acaba de hacerse un descubrimiento importantísimo para la historia de la topografia de la ciudad de México. Sabido es que no se ha logrado determinar

2 "Fragmento de un viaje a México por la ciudad", El Album Mexicano, 1849, en Ruiz Castañeda María del Carmen, La ciudad de México en el siglo XIX, México, Departamento del Distrito Federal, 1974, p 26 (Colección Popular Ciudad de México 9). 
el lugar que ocupó la primitiva Catedral, erigida en 1526 Nosotros en un trabajo especial que nos ha ocupado cerca de seis años, fijábamos el espacio que media entre la torre Occidental de la iglesia Catedral y la parte Sur del cementerio ('atrio?) que era su frente, corriendo las naves hacia el Este, por la parte Norte, casi junto a las puertas principales de la actual iglesia que dan al Sur. Estamos a punto de hacer tan importante descubrimiento. Acaba de aparecer en el cementerio (¿atrio?) de Catedral parte de una columna, que estamos casi seguros descansa sobre una piedra que debe tener la figura de una cabeza de serpiente, de las que formaban el atrio del Templo de Huitzilopochtli. Si a partir de la columna descubierta, se sigue con cuidado la excavación en línea recta hacia el Este, se encontrarán los cimientos y basas de las otras columnas, descansando sobre piedras idénticas a las que citamos antes y descubrirá la planta de la primitiva Catedral.

De la ilustración de los señores Gobernador del Distrito y presidente del Ayuntamiento, es de esperarse fijen su atención en punto tan importante para la historia patria.

México, Agosto 8 de 1881 - Basilio Pérez Gallardo.

El 18 de ese mes con el título de "Excavaciones" La Voz de México avisaba, de los: "Hallazgos arqueológicos en las excavaciones del jardín de Catedral":

.... se han hecho nuevos y valiosísimos hallazgos de inestimable valor para los anticuarios. Muchos de los ídolos han sido encontrados en fragmentos, pero perfectamente reconstruibles. Grandes piedras con jeroglificos aztecas; trozos de obsidiana que se supone serían cuchillos de los sacrificios.

El trazo de la catedral primitiva ha quedado ya determinado con toda exactitud, pues se han hallado los cimientos casi con su alineación regular, y sobre ellos varias otras bases de columna para cuya extracción se trabaja con actividad.

Para el 25 de septiembre, el diario era más explícito y en primera plana en su "Revista Semanaria" se refería a: "El jardín de Catedral y a la proyectada reja de hierro", detallando su diseño y emplazamiento.

El jardín que el Ayuntamiento está formando en el espacio que hay entre las Cadenas y el zócalo sobre que está sentada la Catedral, quedará hermosísimo. No se ha economizado gasto. Las pequeñas avenidas que dividen los prados, de varias formas, que se encuentran en trazo, han sido cubiertas con una gruesa capa de no sabemos qué mezcla parecida a la que el Sr. Riva Palacio mandó que se empleara en el centro del jardín principal A uno y otro lado se han puesto rieles, que al mismo tiempo que aseguran la duración contribuyen a la elegancia. Los prados están ceñidos en torno de pequeńas rejas de hierro, y cuando florezcan las plantas, que en ellos se pondrán, presentarán las apariencias de graciosos canastillos de flores, obras del arte más que de la naturaleza. Actualmente se coloca una cañería que surtirá de agua las fuentes de mármol o de hierro, en cuya construcción hemos oído que se piensa. El alumbrado de gas se ha aumentado de una manera considerable, de modo que si se continúa 
trabajando con el esmero y gusto que hasta ahora, el nuevo jardín ofrecerá un aspecto delicioso. Lo que si creemos impropio, por tratarse del lugar de que se trata, es que se pongan allí estatuas, a no ser que el Ayuntamiento cuide que sean de aquéllas que correspondan a lo sagrado del sitio que se han propuesto embellecer. No harían mal papel, representados en mármoles y en bronces, algunos bienhechores de la ciudad.

En relación con la verja que supliría las antiguas cadenas, el periódico dice que para aumentar la belleza del sitio el "Deán de la Catedral Don Joaquín Primo de Rivera y don José María Padilla" han pensado en que:

Una reja de hierro de tres o cuatro metros de altura con sus respectivas portadas, era una exigencia del buen gusto, del ornato y aún de la moralidad.

Ante la seguridad de la escasez de fondos tanto de la iglesia como del Ayuntamiento, La Voz de México daba solución al problema avalando la generosidad de los citadinos:

No creemos que falten en la católica ciudad personas que se apresuren a contribuir con una pequeñísima parte de su caudal.

Nos prometemos que sobrarán nombres que inscribir en las proyectadas rejas

Una vez ejecutada la mejora, ya no presentarán los muros de la obra monumental más grandiosa de las Américas el aspecto repugnante que suelen presentar en algunas ocasiones, merced al poco respeto y a la indiferencia de muchos de los que pasan. El vicio que busca las sombras hasta en el mismo santuario de la Divinidad y de la virtud, tropezará con una barrera que le detenga.

Quienes estaban inquietos por la clase de estatuas y fuentes que se colocarían en el jardín de Catedral, no tuvieron que esperar mucho para conocerlas, éstas se hallaban ya en territorio mexicano. Al respecto la Cámara de Diputados del Congreso de la Unión en su última sesión de septiembre trató lo relativo a los impuestos que se debían pagar por los objetos que servirían de adorno una vez realizadas las mejoras en Catedral.

El Diario de los Debates, bajo el rubro "Aviso de 1881 " daba cuenta de los acuerdos tomados en esa sesión que había sido presidida por el C. Altamirano, y en la que la Segunda Comisión de Hacienda, después de "examinar la iniciativa de la Secretaría de Gobernación", de acuerdo con el gobierno del Distrito, pedía se dispensara del pago de derechos de importación, "las figuras de ornato destinadas al jardín que se está formando en el Atrio de la Catedral": 
Diario de Los Debates de la Cámara de Diputados. Décima Legislatura Constitucional a la Nación III. Correspondiente a las sesiones ordinarias y extraordinarias durante el primer periodo. Presidencial del C. Altamirano. Sesión del 30 de septiembre de 1881. Tratándose de mejoría que tiende a embellecer uno de los lugares más públicos de nuestra capital, evitando que como hasta hoy es el local un foco de inmundicia y abrigo para malhechores atendiendo ordeno que los derechos cuya exención se pide, son de poca cuantía, tiene el honor de someter a la deliberación de esta respetable Cámara el siguiente: Artículo cinco. Se dispensa el pago de los derechos de importación que causen las piezas de ornato siguientes: Diez fuentes fierro colado, de diversos tamaños. Cuatro estatuas de fierro colado tamaño natural. Seis trozos del mismo metal, para colocación de parásitos (sic). Doce macetas del mismo metal, y cincuenta bancos del propio metal; cuyos objetos se destinan al ornato del jardín que se está formando en el Atrio de la Catedral de esta ciudad. Sala de Comisiones de la Cámara de Diputados. México Septiembre 29 de 1881. Luis Pombo - F. Ogarrio - Enriquez. C. Valle Secretario - Se ha presentado este dictamen.

El altruismo preconizado algunos días atrás no se hizo esperar, los donativos para construir el enverjado que protegería jardín e Iglesia empezaron a llegar. La:respuesta de la ciudadanía del Distrito Federal y de la de algunas de los Estados colindantes, queda registrada paso a paso por $\mathrm{La}$ Voz de México a partir del 2 de octubre y casi siempre en su "Miscelánea":

Para el enverjado del atrio se ha suscrito con veinte pesos el Sr. D. Luis García Pimentel.

El 6 de octubre se citaban los nombres siguientes: "D. Jesús María Barbabosa vecino de Toluca, con el valor de un tramo", y veinticinco pesos el "Sr. D. Javier Torres Adalid". Para el 11 de octubre se anuncia los nombres de quienes colaboraban con el precio de un tramo de reja completo: "D. José María Flores; D. José Rafael Castillo; D. Faustino Goribar. Las señoras Gerarda Pardo de Pavión con medio tramo y la "viuda del licenciado Don Cornelio Prado con cincuenta pesos", al igual que D. Antonio Carbajal. La lista era dilatada, pues a las iniciativas individuales se unían ahora las de algunas sociedades:

LAS SOCIEDADES DE PELUQUEROS Y MESEROS, correspondiendo à la invitación que se ha hecho por medio de la circular que a continuación insertamos, están reuniendo, por medio de cuotas, una cantidad considerable para contribuir a la formación del enverjado del atrio. Bien por los dignos miembros de ambas sociedades. He aquí la circular a que aludimos.

"Los que suscribimos deseamos formar un cerco de hierro en el Atrio superior de la Catedral, muy necesario para guardar el templo de las faltas que cerca de él se comenten y para hermosearlo, pues es uno de los mejores edificios de nuestra república; mas no se cuenta con fondos para tan grande empresa, y 
ocurrimos a la generosidad, de los buenos mexicanos para lograr nuestros buenos deseos.

El presupuesto del Sr. ingeniero D. Juan Cardona, es el de $\$ 17,000$ contando con las cadenas y postes que hoy existen; para que sea más fácil reunir dicha cantidad, hemos convenido en dividir dicho cerco en tramos o divisiones de a tres metros cada uno, siendo el costo de cada tramo de $\$ 183.33$ cs. cuya cantidad deberá entregar el que lo tome, al Sr. D. Rafael Ortiz de la Huerta, persona muy conocida por su posición social y su honradez.

Como está bien demostrado el patrimonio de tan digna Sociedad, ocurrimos a ella para que si a bien lo tiene, reúna el valor de uno o más tramos, en el concepto de que se pondrá en ellos el nombre de la persona o Sociedad que los haya costeado. Suplicamos a vd. se digne dar cuenta con nuestra solicitud, protestándole a la vez las consideraciones de nuestro aprecio.

México. Octubre 8 de 1881 -Joaquín Primo de la Rivera -José María Padilla.

El 15 de octubre La Voz de México, se refería con entusiasmo al Regidor de Paseos por la atención que prestaba a las obras pues además "de dar órdenes y dictar oportunas disposiciones", se ocupaba de vigilar personalmente el avance de las tareas. El periódico daba por un hecho la pronta terminación no sólo del jardín sino también del enverjado y aprovechaba la oportunidad para señalar la conveniencia de que se diera:

... al frontispicio del templo toda su hermosura y elegancia. Nadie habrá dejado de ver que las basas y los capiteles de las columnas, así como las estatuas, los pedestales de ellas, los bajo relieves y muchos de los adornos arquitectónicos del templo, son de mármol y están algo demeritados a causa no sólo del tiempo sino de que antaño fueran maltratados por los que pintaron las magníficas canteras de la iglesia.

Empréndase pues la obra de pulir las partes marmóreas del edificio y hágase en nuestros días aparecer la hermosa Catedral con todas las bellezas arquitectónicas que tiene semiocultas, ahora que se la rodea de un jardín y se levanta una balaustrada que le de mayor realce y majestad.

Puesto en plänta el pensamiento, a él deben cooperar, no sólo la sagrada mitra, sino los particulares, y el municipio....

Ya que reina la paz y la calma y que las mejoras materiales embellecen a la capital por todas partes, no se dejen sin descubrir por completo las bellezas artísticas que están como escondidas y veladas en el frontispicio de la Catedral católica.

Muy pronto entre septiembre y noviembre, el número de donantes pasó la centena. El periódico no dejó de incluir a la mayor parte de los mismos inclusive a aquellos que aportaban pequeñas cantidades como el doctor don Manuel Leal cura de Chimalhuacán, Chalco, quien dio siete pesos, o a las comunidades tales las de la Iglesia de San Sebastián cuyo cura Fr. Nicolás Arias entregó de su parte y de los feligreses de su curato, "cuarenta 
y cinco pesos setenta y cinco centavos". Los dueños de las tiendas $L a$ Sorpresa y Primazera, los señores Fourcade y Coupil obsequiaron el costo de un tramo, mientras que el Sr. Pablo Escandón por sí y por la casa de Barrón contribuía con el valor de un tramo.

La comunidad de la Parroquia de Santa Catarina Mártir, reunió doscientos pesos, y esperaba aumentar esa cantidad.

El 12 de noviembre, $L a$ Voz de México insertó lo dicho a propósito del enverjado por el diario La República el 11 de ese mes, "Desearíamos saber cuántos tramos están ya contratados y cuándo empezará la obra". Por respuesta el periódico católico, afirmaba que todo el trabajo estaba ya concertado con el ingeniero Juan Cardona y que las labores hacía un mes que se habían iniciado, "extendiendo el zócalo por el costado del Sagrario y labrándose la cantera de las pilastras": el mismo diario añadía el 19 de noviembre en su "Miscelánea", que las tareas de aquel "precioso parque continuaban":

Anteayer se empezaron a colocar elegantes fuentes traídas del extranjero.

Dichas fuentes son de hierro, pequeñas y hermosas.

Indudablemente aquel jardín va a ser digno de la cultura de esta ciudad.

De desearse es que si el actual Ayuntamiento quiere concluir ese parque antes del 31 de diciembre, ponga más trabajadores, pues que falta un gran tramo, comprendido todo el frente de la calle del Empedradillo.

El nombre de Juan Cardona representaba una seguridad para el buen desarrollo de los trabajos, este arquitecto había adquirido buena reputación, gracias a dos de sus obras: "la reedificación del Teatro Hidalgo en la calle de Regina (1862) ${ }^{\mathrm{n}}$ y el muy comentado proyecto de penitenciaria que había realizado en 1888 "en equipo con profesores de la Escuela Nacional de Bellas Artes". ${ }^{3}$

El mismo diario, el 11 de diciembre, se dolía de que la luz eléctrica, anunciada "por un periódico" como un hecho, para el primero de diciembre en el espacio y calles comprendidos entre la estatua de Carlos IV y Palacio Nacional, no se había cumplido y sólo se hallaban colocados "cuarenta postes" y si bien, con este necesarísimo adelanto estaba en falta el Ayuntamiento, por lo que tocaba al jardín de Catedral, "la obra estaba concluida".

Hoy por la tarde tendrá lugar la ceremonia de inauguración, a que asistirán el Secretario de Gobernación y otros personajes.

\footnotetext{
${ }^{3}$ Israel Katzman, Arquitectura del Siglo XX, México, Centro de Investigaciones Arquitect6nicas, UNAM, 1973, p. 271
} 
El Ayuntamiento merece un voto de gracias de parte de todos los habitantes de México por la pronta realización de la feliz idea de poner bajo los dominios de Flora, sitios malaventurados y sacrílegamente usurpados por bastardas y repugnantes soberanías.

El anónimo reportero felicitaba al regidor Barreriro y a quienes con su altruismo harían posible el esmero y belleza del jardín pues éste era "realmente de muy buen gusto", y su costo nada elevado para las autoridades, "Ya que la ciudadanía había aportado la suma mayor y sus donativos monetarios eran muchos y cuantiosos". De igual manera la sociedad contribuyó con buen número de plantas, por lo que el regidor ofrecía dar a conocer la lista de tan liberales personas, y La Voz de México seguía con la descripción de ese jardín cuyo aspecto:

Es hermosísimo. Está dividido en veinticinco alegres prados cubiertos de césped en toda su extensión: Hoy por la tarde tendrá lugar la ceremonia de la inauguración, a que asistirán el Secretario de Gobernación y otros personajes ${ }^{4}$

El regidor Eugenio Barreriro pese a que el enverjado y el jardín estaban inconclusos, llevó a buen fin su promesa de inaugurar ese parque antes del 31 de diciembre.

La relación de las personas obsequiadoras, cuya magnanimidad había hecho posible tal variedad de verdura - en ese tan singular y bello sitiosería dada a conocer por Barreriro hasta el 21 de diciembre, junto con la cuenta de gastos, es decir las cantidades recibidas y acordadas por el Ayuntamiento para la formación del jardín del atrio; así como el cauce dado a tales ingresos. 5

Junto a esa enumeración de donantes y de desembolsos efectuados, el periódico aclaraba que la parte terminada del jardín sólo era la comprendida en el ala sur del atrio, por lo tanto no es de extrañar que el domingo $1^{\circ}$ de enero de 1882 , también justifique el porqué las rejas no se instalaban todavía:

El enverjado de la catedral. Ha comenzado a colocarse el primer tramo. Varios colegas de la capital han manifestado que no les agrada, y le califican de pequeño y raquítico, sin advertir dos cosas: primera que son escasos los recursos con que se cuenta para la obra, y era preciso sujetarse a ellos: segunda, que se ha procurado no dar mucha altura a la reja, ni sobrecargarla de adornos, para no interceptar en gran parte la vista del templo, como algunos periódicos llegaron a temer que sucediera. Por lo demás la dirección de la obra está a cargo

\footnotetext{
${ }_{5}^{4}$ Se incluye en el apéndice documental el artículo completo.

${ }^{5}$ Idem.
} 
de uno de los más hábiles ingenieros de la capital; y nos parece que para juzgar acertadamente de ella es necesario esperar a que se termine para verla en conjunto y no sólo en una de sus partes más pequeñas.

El grato espectáculo de la parte terminada no conmovió a ciertos sectores de la ciudadanía y con gran falta de civismo y haciendo gala de incuria, la suciedad y porquerías continuaron proliferando en torno a la Catedral, así lo hacía saber La Voz de México el 5 de enero:

Suplicamos a quien corresponde se proceda desde luego a continuar la construcción del Jardín del atrio, evitándose así que aquel lugar siga convirtiéndose en inmenso basurero.

Ante esa pública advertencia el señor Barreriro asegura al diario, que los trabajos de embellecimiento van a seguir y que para ello pidió permiso al Ayuntamiento. El periódico (13 de enero) a su vez indica que esa tarea sería hasta "la próxima semana".

No obstante tal afirmación, para el 24 de enero todo seguía detenido, La Voz de México protestaba, pues el basurero se había extendido aún más por lo que el reportero aconsejaba: "bueno sería que el Ayuntamiento apresurara esos trabajos cuanto antes", y es hasta el 6 de febrero que según el mismo periódico:

Han comenzado a acumularse los materiales para la construcción del jardín del atrio, por el lado que ve al Poniente. El gasto de 6,500 pesos importe de la obra de terminación del jardín del atrio fue autorizado por el Ayuntamiento.

Pese a la buena voluntad de Eugenio Barreriro, al decir de José María Marroquí, fue hasta febrero de 1887 que jardín y enrejado quedaron totalmente terminados. Marroquí enumera varias de las razones de tal edición, y es también gracias a ese escritor que podemos saber que la obra de cantería la hizo el "maestro en arte" D. Pablo González y que la herrería se realizó en los talleres de dos herreros, uno en la calle de Zuleta (hoy Venustiano Carranza) del francés Richaud y el otro en el del mexicano don Genaro López Marroquí en su tomo III de La ciudad de México amplía toda esta valiosa información y narra que para 1887 , "cambiaron de sitio las esculturas, [las dos cruces] que quedaban afuera del enrejado" una de ellas la conocida como Cruz de Mañosca, mismas que se restauraron y pusieron a resguardo dentro del atrio. También relata, que el enrejado de

${ }^{6}$ José María Marroqui, La Ciudad de México, Tomo III, México, Jesús Medina Editor, 1969, pp. 279-281. 
la espalda de la Catedral, "en la calle de las Escalerillas" (hoy Guatemala) se puso gracias a la munificencia de anónimo bienhecnor y que en él se siguió el mismo estilo que en el del frente. Ahora bien como una obra llama a otra, varios arreglos se efectuaron en ese lapso, en el perímetro del jardín del atrio de la Catedral.

Ahora que nuestra iglesia catedralicia está dañada y en grave peligro, debido a temblores de tierra, asentamientos y hundimientos del subsuelo, icuánto añoramos! la generosidad de esos ciudadanos que nos precedieron y que por su religiosidad, fe y amor a su ciudad no escatimaron esfuerzos para mejorar la imagen que el derredor del templo exigía. 


\section{DOCUMENTO No. 1}

\section{REMITIDO}

Sres. R. R. de la Voz de México-_ Presentes.

C. de vdes. 19 de Diciembre de 1881.

Queridos amigos míos:

Confiando en la bondad de Vdes., me tomo la libertad de suplicarles se sirvan publicar en su acreditado diario los adjuntos documentos, que además de encerrar interés general, ponen a cubierto cualquiera apreciación de mala ley que pudiera hacerse de la inversión de los fondos acordados por el Cuerpo Municipal para la construcción del jardín del atrio de la Catedral.

Dando a vdes. las gracias más expresivas por este favor, me repito su afmo. amigo y S. S. Eugenio Barreiro.

Comisión de Paseos - Acordada por el Ayuntamiento la construcción de un jardín en el atrio de Catedral, se han autorizado por diversos acuerdos de Cabildo, los gastos necesarios para llevar a efecto las obras correspondientes.

Como está terminado ya el jardín en la parte Sur del atrio referido y como la oficina del digno cargo de $\mathrm{Vd}$. ha verificado los pagos acordados por la Comisión de Paseos, previo el Visto Bueno de la misma; he de merecerle se sirva formar y remitirme una noticia pormenorizada de las cantidades autorizadas para la construcción de dicho jardín, expresando la fecha de los acuerdos relativos y la inversión que se dio a esas cantidades, incluyendo a la vez en esa noticia el donativo de $\$ 300$ que hizo para el mismo objeto el Director del Nacional Monte de Piedad, y en que fue empleado dicho donativo.

Libertad en la Constitución. México, Diciembre 9 de 1881.- Eugenio Barreiro.-Al Administrador de Rentas Municipales - México.

Un sello que dice: Administración de Rentas Municipales.-- México.

Tengo el honor de acompañar a Vd. la noticia de las cantidades acordadas para la formación del jardín del atrio de la Catedral y la inversión dada, advirtiéndole que todos los comprobantes constan en las pólizas respectivas.

Lo que digo a vd. en debida contestación a su oficio relativo de 9 del presente.

Libertad en la Constitución. México, Diciembre 15 de 1881.-Antonio Sola.Al C. Regidor Eugenio Barreiro.

Administración de rentas municipales.

Noticia de las cantidades acordadas por el ayuntamiento para la formación del jardín del atrio de Catedral con expresión de la inversión dada a estas mismas cantidades. 
Para la compra y flete de ocho fuentes de fierro inclusos 1,000 pesos que se tomaron para la festividad del

15 y 16 de Septiembre Acordado para las cañerías que conducen el agua a las fuentes.

Para gasto y jornales

Id. id. id....

Id. id. id....

Id. id. id...

Id pago de estatuas, donativo hecho por el Nacional Monte Del frente

Pagado por tierra y barro

Id. por materiales de construcción $\quad 139.31$

Id. por varas de canastillo de fierro

Id. por varas de calzada de cimento romano...

Id. por raya de peones.

Id. por obras de cantería

Id. por estatuas y macetones de bronce las primeras y fierro los segundos

Id. por el valor de ocho fuentes de fierro, y el flete de Veracruz a México

México, Diciembre 15 de 1881 - J M. de Olaguíbel.-Vo. Bo. Antonio Sala

Nota.-De los $\$ 8,436.51$ es que figuran como gastados hay que deducir el valor correspondiente de cuatro fuentes que están depositadas en el Montepio y deben servir para ser colocadas en la parte Poniente, cuando se continúe la obra. Estas, con alguna existencia de rieles y otros materiales importan la suma de $\$ 1,850$. De manera que el gasto del jardín en toda la parte Sur, importa $\$ 6,586.51$ cs. Las personas con quienes se han contratado los materiales de la obra son las siguientes:

La tierra vegetal, con la empresa de ferrocarriles del Distrito Federal.

La construcción de calzadas, "Cimiento Portland", con los Sres. Gibbon hermanos.

La canastilla de fierro que circunda los prados, con el herrero J de la Torre.

Las rayas, mediante la correspondiente memoria, las verificó el $\mathrm{Sr}$. ingeniero D. Romualdo Rivera. 
La comisión no ha tenido otra intervención, que la directiva, entendiéndose en el cumplimiento de los contratos respectivos, y visando los recibos que ha pagado directamente la tesorería municipal.

México, Diciembre 16 de 1881 - E. Barreiro.

La Corporación Municipal, por conducto de la Comisión de Paseos, dá las más expresivas gracias a las personas que a continuación se expresan, por los donativos que han hecho para el adorno y embellecimiento del jardín que nuevamente se ha construido en el atrio de la Catedral.

Sra. Gorozpe de Lizardi, tres tuyas occidentales, dos hules, una azalea y una piña anona.

Sra. Garza de Nájera, un pino y un "pittos phorum".

Sra. Falgar de Barreiro, un cedro.

Sra. Vizcarra de Kinght, una hermosa planta "fornim tenax".

Sra. Buch de Iglesias, una polígala.

Sra. Olivia, una "tornelia fragans".

Una señorita que no quiso dar su nombre, un hermoso cedro de tres metros de altura.

Srita. Sierra y Ontiveros, dos rosales, una planta espina conocida vulgarmente con el nombre de "Corona de Cristo" un naranjo grande y una pitaya

Sra de Ignacio Martínez, dos injertos de rosa.

Sra Camargo de Sola, un hermoso "pittos phorum".

Sra. Vallejo de Barreiro, ocho o diez plantas de poca importancia.

Sra. Guadalupe Bross, tres docenas de plantas pequeñas y un hermoso "pittos phorum".

Sra. Zozaya de Escalante, dos cordilinas.

Sra. Coblentz, una pequeña palma.

Sra. Games de Bulnes, cuatro hermosas plantas finas y de diversas especies

Sra. Chávez de Paulin, dos jazmines grandes y un guayabo de la India.

Sra. Concepción $\mathrm{N}$. de Urquiaga, dos cordilinas.

Sra. Cañas de Limantour, doce injertos de rosa.

Sra Marguett de Limantour, una yuca grande, una arabia y un acanto.

Sra. Topete de Llano, un laurel de la India.

Srita. Angela González Buch, dos grandes y her mosísimas azaleas.

Sra Servín de Capetillo, una hortensia y dos plantas más de diversas clases.

Sra Aponte, dos pinos.

Sra Lizardi de del Valle, cuatro plantas finas de diversas clases.

Sra. Luz Arias, dos magueyes.

Sra. Solórzano de Romo, cuatro notables cedros que vulgarmente se conocen con el nombre de esferas, un injerto de rosa y una berengena.

Sra. Gzophe de Sapiain, un naranjo de la Martinica.

Sra Aguirre un hermoso clavo grande.

Sra Azcárate de Tavera, doce macetas de diversas especies, todas plantas muy finas y perfectamente bien cultivadas

Srita. Concepción Gómez Parada, dos tuyas grandes.

Sra. Guadalupe Delgado, once plantas pequeñas.

Sra. Vertíz de Cortina, dos edeclinius. 
Sra. Seoane de Bajes, una planta grande de la familia de los hules.

Sra. Terreros de Rincón Gallardo, algunos cactus, producto de una de sus fincas y que llaman la atención por lo bien elegido de su especie.

Sr. Cappson, tres ejemplares de magueyes (henequén) de Yucatán.

Sr. Gutiérrez Vitori, cuatro plantas diversas clases.

$\mathrm{Sr}$. Wangool, doce plantas de la familia de los cactus, esmeradamente cultivadas.

Sr. José Revueltas, dos plantas notablemente hermosas.

Sra. Carlos N. dos árboles cuya especie no es conocida en esta capital; se espera su florescencia para que puedan ser clasificados.

Sr. Benito Coblentz, cinco plantas diversas clases.

Sr. Ramón Gúzman donó veinticinco rieles.

La comisión ocurrió al Sr. D. Tomás Braniff con el objeto de obtener un donativo para la obra, de la compañía del ferrocarril de Veracruz, pero se le manifestó que los estatutos prohibían ese género de donaciones, sin embargo, que estaba en la mejor disposición para hacer algo en bien de la ciudad, y efectivamente prestó un buen servicio de dar ciento veinte rieles, con peso de 8,800 libras al precio ínfimo de medio centavo libra, pudiendo estimarse verdaderamente como un donativo.

Sr. D. Ricardo Sáinz, cincuenta pesos

Sres. Gibbon hermanos, un becerro de piedra artificial.

Sr. de Gress, una máquina para podar zacate.

Sr. D. Francisco de A. Prida, de la manera más expontánea y galante, donó doce uniformes de paño de muy buena clase, perfectamente construidos y doce sombreros, con cuya ropa se ha vestido a los jardineros que cubren el servicio del atrio.

El Sr. D. Juan Bajes, cooperó con el donativo de algunas antigüedades que se hallan colocadas en el pequeño monumento construido en el jardín.

México, Diciembre 15 de 1881. E. Barreiro.

EL JARDIN DEL ATRIO - En la sección de remitidos publicamos hoy el que nos ha enviado el Sr. Regidor D. Eugenio Barreiro, respecto a la inversión de fondos destinados al jardín del atrio y de los donativos de varias personas.

MAZATLAN._El edificio conocido con el nombre "Hospicio Militar" sufrió un derrumbe en la noche del 5 del pasado. Se ignora cual fue la causa.

La Voz de México.

21 de diciembre de 1881 , p. 2

\section{DOCUMENTO No. 2}

\section{REVISTA SEMANARIA}

El alumbrado eléctrico-El jardín de Catedral.

- Una inscripción - Funciones de la Purísima - Novedad teatral.

Recordamos que hace algunos días un periódico anunció que el día lo del 
mes que corre estarían alumbradas definitivamente, con luz eléctrica, todas las calles que se extienden desde la estatua de Carlos IV hasta el palacio nacional. Nosotros lo creímos, pues veíamos que se habían colocado, como lo están, cerca de cuarenta aparatos, distribuidos en la extensión que se acaba de determinar. Pero el 1o. de Diciembre llegó, y va ya a terminar la primera quincena, sin que el anuncio se haya verificado. Todo el empeño de la empresa equedará reducido a haber puesto cuarenta o más postes, que por cierto no son adorno para la ciudad?

El nuevo alumbrado es necesario, pues el antiguo ya no cumple con su objeto. Parece como córrido y avergonzado de que se le dé de mano, después de tanto servicio.

La espectativa en la nueva mejora ha sido hasta cierto punto perjudicial, pues el alumbrado de gas, desde que se ha pensado en sustituirle, ha disminuido en intensidad, $y$ ha habido noches en que la ciudad ha presentado el aspecto que presentaría allá en los tiempos anteriores a Revillagigedo. Está bien que se apaguen las escasas luces, cuando, como en estos días, la luna parece no querer consentir en que el arte se ponga frente a frente de la naturaleza, usurpándole a ella sus títulos y prerrogativas de reina de la noche; pero no lo está que se nos deje a oscuras como sucede en muchas ocasiones, sólo porque se presume que la luna alumbrará, aunque no alumbre, o porque alumbre unos cuantos momentos. El Ayuntamiento debe cuidar de que la empresa cumpla exactamente con sus compromisos. Habiendo, como hay, una contrata, nada tendrá que desembolsar, y sus cajas quedarán tan llenas o tan vacías, como se encuentren.

Lo contrario há sucedido con el jardín, que no ha mucho se comenzó a formar frente a la Catedral. Se halla concluida la obra, y bien concluida. Hoy por la tarde tendrá lugar la ceremonia de la inauguración, a que asistirán el secretario de Gobernación y otros personajes.

El Ayuntamiento merece un voto de gracias de parte de todos los habitantes de México por la pronta realización de la feliz idea de poner bajo los dominios de Flora, sitios malaventurada y sacrílegamente usurpados por bastardas y repugnantes soberanías. En lo particular, el regidor D. Eugenio Barreiro es digno de todo encomio, por la asidua dedicación y celoso afán y noble desprendimiento con que se consagró á demostrarnos que la obra no que quedaría, como tantas obras, en proyectó, descuidando aún sus propios negocios, y con perjuicio tal vez de sus intereses. Es acreedor también á alabanza, por el gusto exquisito que ha precedido a la formación del jardín, y por la economía con que lo ha hecho, cosa extraña y verdaderamente prodigiosa en todo aquello, cuyos costos se sacan de las arcas públicas. La mayor parte de las plantas le han sido regaladas, y, según le hemos oído, se propone publicar una lista de las personas de quienes las hubo.

El aspecto que presenta el jardín es hermosísimo. Está dividido en veintisiete alegres prados cubiertos de césped en toda su extensión. Se ven allí mezclados en agradable y poética confusión, vegetaciones de todos los climas, así de los glaciales como de los cálidos. Entre los árboles se levantan a poca altura, el cedro y el pino, el frésno y el ahuehuete, la hulla y el nopal, el plátano y el guayabo, el naranjo y la palma; entre los arbustos descuellan la lactana y la salandria, el jazmín de Italia y la magnolia, la polígala y la mosqueta; y entre las plantas y las flores sobresalen los geranios y los mirtos, las violetas y las 
sempiternas, los claveles y las fusias, los órganos y las bisnagas, los lotos y las rosas. Sería largo de enumerar tanta belleza vegetal como se reunió y supo reunir en el pequeño espacio de veinte mil metros cuadrados, que eso medirá a lo sumo el jardin que describimos.

Por una coincidencia, los prados son tantos en número como los Estados de la república, y parece que se tuvo empeño de ponernos allí algo que nos recordase este ó aquel sitio más o menos pintoresco de la gran variedad de nuestro territorio.

Al pasar por aquel montículo de musgosas rocas, de áspera y seca vegetación como ellas, se antoja al que pasa, que hace su primera entrada a las áridas y mustias regiones del Mezquital. Al avanzar, tropieza de repente con un pedazo de tierra que parece arrancado, con todas las galas con que le enriqueciera la naturaleza, de los alrededores de Cuernavaca o de Orizaba. Más allá la fragancia del cedro y la frescura del pino, casi le persuaden de que se encuentra cerca del Monte de las Cruces o a las faldas occidentales del Popocatépetl. Las flores le hacen creer transportado, como por encanto, al centro de la ciudad; un risueño campo de Abril o de Octubre, cuando la primavera y el estío dan testimonio en las comarcas michoacanas de su exuberancia maravillosa, o bien un vergel de tantos como forman el orgullo y la delicia, el atractivo y la gala de los admirables pueblecillos de San Angel y de Mixcoac, y de las históricas ciudades, hoy en ruina, de Tlalpan y de Xochimilco.

Hay tres prados de verdadera poesía, aunque de carácter enteramente diferente. Dos de ellos, están cubiertos de injertos de rosas amarillas, rojas y blancas. Cuando florezcan todas, darán la idea de un exquisito ramillete formado para obsequio en el cumpleaños de una reina.

El otro prado representa las ruinas de un templo. Una columna se ha atrevido a permanecer en pie entre mil piedras amontonadas allí como por la misma mano del tiempo, y entre basas y capiteles fuera del sitio en que el arte del hombre los colocara. No falta vegetación en este montículo, pero es de aquella triste y sin follaje, arañosa y cubierta de espinas, que se desarrolla y nutré a expensas de la atmósfera. Una que otra florecilla, que parece brotar de un tronco seco, revela allí la presencia de la vida Debía darse allí un sitio al amarillo jaramago para mejor persuadir la verdad histórica que se trata de representar. La columna y las basas y los capiteles son obra de dos pasadas generaciones, distantes una de la otra no solo por la fe y la cultura, sino por el tiempo y por los lugares; de dos razas que se han venido a fundir, después de algunos siglos, por el fuego de la caridad, en el puro crisol de catolicismo. Los escombros que alli se ven han sido recientemente exhumados, y fueron testigos de los cultos que al demonio tributó la gentilidad azteca, durante largas centurias, y lo fueron también de la adoración en espíritu y en verdad, que aquella misma, convertida por apóstoles de heroica virtud, y en unión de los conquistadores, tributó después al único y verdadero Dios. El ayuntamiento ha puesto una inscripción que recuerda este acontecimiento histórico. Héla aquí:

"Piedras del teocal sangriento del Huitzilopoxtli, empleadas después en el templo que los españoles erigieron en este sitio a la fe cristiana."

A tanta belleza natural se agrega la del arte. Se ven de trecho en trecho grandes macetones de hierro, y estatuas de bronce, hechas por ejercitado buril. Cuatro primorosas fuentes se han colocado hasta ahora "Son de hierro como 
los macetones y bronceadas como las estatuas. Los surtidores de las dos más grandes tienen una figura verdaderamente artística. Sobre dos delfines, cuyas colas se estrechan, descansa una concha, en que como en su trono se ve de pie y armado de su tridente y resonado un caracol, un Neptuno, no en su decrepitud, tal cual no es conocido, sino casi en su infancia. Parece jugar con el cetro y con la magestad. Los dos surtidores de las fuentes más pequeñas, son un grupo gracioso de tres niños desnudos, dos de los cuales pretenden levantar, lo más alto que pueden, al otro, a fin de que beba el cristalino líquido en que todos se bañan.

En suma, el nuevo jardín, es bello y convida a pasear por sus avenidas. Nosotros vamos a él a recibir todas las mañanas los favores de Febo, ahora que el invierno comienza a gozarse en hacernos tiritar.

La Voz de México.

Domingo 11 de diciembre 1881, p. 1 .

\section{DOCUMENTO No. 3}

\section{LA CATEDRAL DE MÉXICO}

Hoy que con ocasión de las reformas que se están haciendo en el atrio de ese templo, se habla con frecuencia y en todos nuestros grupos sociales, acerca de la construcción de la Catedral que hoy existe y de la iglesia que antes de ella se había construido y se demolió, creemos que complacerá a nuestros suscriptores la lectura de lo que respecto del templo metropolitano de México imprimió el año de 1668 el Dr. D. Isidro Sariñana:

"Siendo esta populosa ciudad de México, como corte imperial de NuevoMundo, centro donde se habian de tirar a toda la circunferencia de tan dilatado imperio, las líneas de la política española y religión cristiana, trató su famosísimo conquistador D. Fernando Cortés, cuyo nombre dignamente vincularon a la inmortalidad de la memoria sus hechos de poner en perfección esta República. Distribuyó entre los conquistadores sus solares, señaló lugares para iglesias y dio principio a la mayor antigua, en el mismo donde tenía la gentilidad su principal y más suntuoso templo, cuyo sitio fue siempre de más altura y solidez que el resto de la ciudad, formado aun antes de su fundación primera dentro de la laguna, pequeña isleta donde aquellos primeros esploradores que destinaron los mexicanos, buscando lugar, encontraron su primera colonia, y hallaron el tunal que desde entonces quedó por armas de la ciudad. Empezó, pues, D. Fernando Cortés la fábrica de iglesia antigua, disponiendo que se levantasen sus columnas sobre unos ídolos grandes de piedra, que sirviéndoles de base, fuesen hollados de la siempre firme e incontrastable columna de nuestra sagrada religión cristiana. Continuó la fábrica de esta primera iglesia, a grande prisa, D Sebastián Ramírez de Fuen Leal, Obispo de Santo Domingo, que siendo presidente de esta audiencia, gobernó este reino desde el año de 1531 , hasta el de 35 . Insistiendo siempre en su prosecución la 
solicitud religiosa, y pastoral vigilancia del $\mathrm{Sr}$. D. Fr. Juan de Zumárraga, se consiguió su última perfección en el gobierno de D. Antonio de Mendoza, hermano de marqués de Mondejar, del hábito de Santiago, comendador de Socuellanos, primer gobernador, con título de virrey en las Indias, a cuya madura prudencia y vigilantísimo cuidado debió este reino su consumación en lo político.

"Aunque esta primera iglesia tenía la perfección en su arquitectura, que bastaba para la decencia del templo, y capacidad suficiente para todas las funciones de catedral; con todo, no pareció a nuestros católicos reyes, que era la que pedía a su magnificiencia la piedad, y la que demandaba a su religión la opulencia de este Nuevo-Mundo, reservado por la Divina Providencia a su corona. $\mathrm{Y}$ así, el año de 1552, gobernado por el señor emperador el principe prudente, D. Felipe II, despachó cédula a la real audiencia y virrey de esta Nueva-España, que lo era entonces D. Luis de Velasco, el primer caballero del hábito de Santiago, para que se tratase de edificar nuevo templo con la suntuosidad que convenía a la grandeza de este reino, y a la cristiana generocidad de sus virreyes. El deseo de los aumentos en el culto, nacido del fervor religioso de este católico pecho, abrasó en esta ocasión a $\mathbf{S}$. A aun la advertencia de los imposibles, pues lo eran entonces la ejecución de sus intentos; porque como acreedores de su real piedad, embargaban en aquel tiempo casi todo su patrimonio de las Indias otras muchas magníficas obras, que a expensas suyas, o se trataban de empezar, o ya comenzadas se continuaban en esta imperial corte, como la real universidad, que por cédula del señor emperador, tuvo principio su fundación el año de 1553, día de la conversión de San Pablo; obra que no admitía dilación, siendo indispensablemente necesaria para crianza y educación de sujetos, que como maestros habían de labrar después nuevos aumentos al más importante edificio espiritual de esta nueva iglesia El convento e iglesia real de San Agustín de esta ciudad, que se comenzó con la solemne colocación de su primera piedra en 28 de Agosto de 1541, para cuyo hermoso edificio dio el señor emperador.... 162,400 pesos, y otras muchas obras, que evitando la prolijidad perdono, aunque con renuncia por lo que cedan en honor y gloria de nuestros reyes católicos de España.

"Por estas razones se dilató el principio de la nueva fábrica hasta el año de 1573, en que gobernando D. Martín Enríquez, del hábito de Santiago, y siendo Arzobispo electo tercero de esta iglesia D. Pedro Moya de Contreras, que fue el primer inquisidor de este reino, y murió en los de Castilla, presidente del consejo de Indias y segundo patriarca de ellas, se puso la primera piedra de ellas en el sitio más eminente y oportuno de esta ciudad, inmediato a la iglesia antigua, con ánimo que demolida después ésta quedase el lugar que ocupaba por atrio o cementerio en la parte anterior del nuevo templo.

"En el espacio de 42 años, desde el de 573 hasta el de 615, se acabaron los cimientos, previniendo en su profundidad, latitud y solidez, la permanencia del edificio, contra la natural flaqueza y debilidad del suelo, levantáronse los muros de toda la circunferencia del templo, a más de la mitad de su altura; las paredes trasversadas de las capillas y las columnas, algunas hasta los chapiteles, y otras hasta los últimos tercios, y se cubrieron de bóveda de lacería, a todo el resto de primor los vestíbulos o entradas que corresponden a las puertas o entradas colaterales de la capilla mayor que llaman de los Reyes, la sala capitu- 
lar y las cuatro primeras capillas, dos por cada banda: debióse tan adelantado progreso en la fábrica, a la celosa vigilancia de los Exmos. señores virreyes que en este tiempo gobernaron, que fueron D. Martín Enríquez, que gobernó hasta el año de 1580 (siete después de principiada la obra); $D$. Lorenzo Suárez de Mendoza, conde de Coruña, del hábito de Santiago, que gobernó hasta el de 83; D. Pedro Moya de Contreras que le sucedió y fue virrey hasta el de 86; D. Alvaro de Zúñiga Manrique, que lo fue hasta el de 89; D. Luis de Velasco el segundo, del hábito de Santiago, hijo del primero y regidor de esta nobilísima ciudad, hasta el de 96; D. Gaspar de Zúñiga y Acevedo, conde de Monterrey, del hábito de Santiago, hasta el de 603; D. Juan de Mendoza y Luna, del hábito de Santiago, marqués de Guadalcázar, que en los primeros de su gobierno remitió a la magestad del rey nuestro señor, D. Felipe III, una relación del estado que tenía la obra, con la monta de su fábrica, hecha por Alonso Pérez de Castañeda, insigne maestro de arquitectura. S. M., reconocido el Estado y virta la traza de la obra, aplicó todas sus católicas atenciones a esta materia; y como si fuese única a los cuidados de su real providencia, siendo por de religión, dignamente primera en los aprecios de su piedad, despachó cédula en 21 de Mayo de 1615, y con ella, otra nueva montea que había hecho Juan Gómez de Mora su arquitecto, dando esta órden al virrey marqués de Guadalcázar: 'luego que la recibáis, procuraréis juntar las personas más prácticas e inteligentes que ahí hubiere en la arquitectura, para que habiéndose visto todo, se elija la mejor traza'."

\section{La Voz de México.}

20 de octubre de 1881, p. 2

\section{DOCUMENTO No. 4}

\section{LA CATEDRAL DE MÉXICO}

En la misma cédula, mandó S.M., que se nombrase un oidor por superintendente de la fábrica, para que a presencia de su autoridad e instancia de su cuidado, tuviese más breve complemento la obra; esto fué añadir mejoría lo mejor, pues en sentencia de San Ambrosio, siempre la presteza fué realce y recomendación del obsequio. En conformidad de esta real cédula, siguiendo la traza que pareció de mayor suntuosidad y hermosura, se continuó a toda prisa la obra; y en el gobierno del Exmo. Sĩ. D. Diego Osorio Pacheco, del hábito de Santiago, marqués de Serralbo, se demolió la iglesia vieja y se paró y colocó el Santísimo Sacramento, en la sacristía mayor de la nueva, donde estuvo, y se celebraron los oficios divinos desde el año de 26 hasta el de 41. Cerróse la capilla del sagrario de los curas que es la primera, por la parte del Mediodía, al lado de la epístola; su cerramiento y lazos son de cantería, a proporción de las otras bóvedas que hasta entonces se habían hecho: cerróse también la capilla de San Isidro Labrador; inmediata a la antecedente, en cuya bóveda se varió la obra, disponiendo S.E., con parecer muy deliberado de los más diestros artífi- 
ces de aquel tiempo, se hiciese más ligera, atendiendo en esto su providencia a la permanencia de sus primeros pobladores; repite esta ciudad, experimentando cada día la breve duración de sus obras y la ruina de sus edificios. No se negaron en esta ocasión a la hermosura, las atenciones que se dieron a la consistencia de la fábrica, en la novedad de esta obra de bóveda; así todo se convexó, se hermoseó con lazos, largas y figuras de medio relieve en yeso con perfiles dorados: acabóse el año de 1627, siendo comisario de la fábrica el Lic. D. Diego Avendaño, oidor de esta real audiencia. El de 29 sucedió la última y mayor inundación que ha padecido esta ciudad, causa porque necesariamente se suspendió por algunos años la obra, y aun se renovaron los intentos antiguos de mudar la ciudad a lugar más oportuno.

Por los fines del año de 635, gobernando el Exmo. Sr. D. Lope Diez de Armendaris, del hábito de Santiago, marqués de Cadereita, y teniendo la superintendencia de la fábrica, por cédula especial del rey nuestro señor $D$. Felipe IV, el Dr. D. Pedro de Guerra, deán de esta santa iglesia, se instauró la continuación de la obra con tal fervor, que el celo de S E. y continua asistencia del deán, se compensó la interrupción que había tenido en el tiempo antecedente, con los muchos aumentos que tuvo en éste, pues en él se labraron y acabaron perfectamente las dos bóvedas de la nave mayor, sobre la capilla de los Reyes, subiendo los muros de ellas desde la mitad de las cuatro ventanas que tiene colaterales, y asimismo tiene cinco bóvedas de las naves procesionales, tres al lado del Evangelio y dos al lado de la epistola, que son las primeras por el lado del Septentrión o cabeza de la iglesia, levantando desde la imposta o chapitel que corona sus capillas, las formas o semicírculos en que están compartidas las ventanas, y sacando a su correspondencia desde sus chapiteles de las columnas los arcos sobre que asientan estas cinco bóvedas, cuya obra se dirá después en la descripción de la fábrica. En tiempo del Exmo. Sr. D. Diego López Pacheco, marqués de Vilena, duque de Escalona, se techó de madera un grande espacio de la nave mayor, para pasar a el Santísimo Sacramento, como se hizo, en 29 de Septiembre de 641; obra aunque interina, de mucha importancia para el consuelo del pueblo, que no podía asistir, sino muy limitado en la celebridad de las fiestas en la sacristía mayor, donde había estado hasta entonces; y sin duda, a no haber sido tan breve el tiempo de su gobierno, hubiera tenido en él muy crecidos adelantamientos la fábrica, por la heroica generosidad de su heroico pecho, bien conocida y satisfecha con el particular afecto que en estas partes le conciliaron sus prendas, añadió al principal y general amor que por la inmediata representación del rey nuestro señor; siempre a sus virreyes, tiene, la constantísima fidelidad de este reino. La misma brevedad del tiempo no dió lugar a notables aumentos de la obra, como se debían esperar en el gobierno del Sr. D. Juan de Palafoz y Mendoza, Obispo de Puebla, que gobernó desde 10 de Junio hasta 23 de Noviembre de 42.

Sucediole el Exmo. Sr. D. García Sarmiento Soto Mayor, del hábito de Santiago, conde de Salvatierra, en cuyo tiempo, estando la fábrica por comisión particular de S.E., al cuidado del Ilmo. Sr. D. Pedro Barrientos Leonelin, tesorero entonces de esta santa iglesia, despues chantre, provisor y vicario general del Arzobispado, y comisario general de la Santa Cruzada, que murió Obispo de la Nueva Vizcaya, hizo la bóveda de la capilla de la Concepción y una de las naves procesionales que es la correspondiente a la capilla de San 
Pedro, con que quedaron perfeccionadas por cada lado, en correspondencia tres bóvedas procesionales y todo el medio que les corresponde: la nave mayor, desde la capilla de los Reyes, se cubrió por entonces zaquizami o media tijera de madera, elevado a toda la eminencia de la bóveda de la capilla mayor, y labrado con tanta fortaleza y aliños, cuantos pudieran atender el cuidado y el arte, si fueran muy de la primera intención de la planta. Quedó esta parte de la iglesia lucida, desahogada, y capaz para todas las funciones eclesiásticas, que pudo, sin embarazo, estrenarse por Febrero de 45, con la consagración del Ilmo. Sr. D. Juan de Mañosca, Arzobispo de México; acto que por la pompa de lo ceremonial y numerosidad del concurso, pedía toda la capacidad de un templo muy entero; de aquí acaso nació el tenerle por acabado Gil González Dávila en su Teatro Eclesiástico de las Indias, que aunque dice haberlo así escrito S.I., lo contrario se convence de la carta de gracias que le escribió el rey nuestro señor D. Felipe IV, en 4 de Octubre de 48 , dándoselas de lo que había hecho en servicio de ambas majestades; no menciona el complemento de esta iglesia, cosa que no omitiera S.M., siendo tan de su deseo, ni menos la represión si se hallara en materia tan grave siniestramento informado. Ni acuso la fidelidad del autor, atribuyo sí este y semejantes deslices, a la distancia, que en esta y otras materias debilita muchas veces lo genuino de las noticias, padeciendo en tan larga navegación, lastimosas averías la verdad, desdicha bien llorada de estos reinos.

La Voz de México.

21 de octubre 1881 , p. 2.

\section{DOCUMENTO No. 5}

\section{LA CATEDRAL DE MÉXICO}

El 13 de Mayo de 1648, entró en el gobierno, con título solo de gobernador, el Sr. D. Márcos de Rueda y Torres, Obispo de Campeche, y por su muerte; gobernó la real audiencia desde 22 de Abril hasta 3 de Julio de 50, día en que entró en México el Exmo. Sr. D. Luis Enríquez Guzman, conde de Alva, de Aliste, del hábito de Alcántara, en cuyo tiempo vista la eficacia y reconocido el ornato con que se aplicó todo el celo de S.E. a la prosecución de su obra, empezó a ser posible a los nacidos, llegarían a gozar el feliz y tan deseado día de la dedicación de esta iglesia.

Estimulado de su mismo celo el Exmo. Sr. conde de Alva, la emprendió con tanta resolución y eficacia, cuanta pedían todos los deseos de la América. Uno de los más importantes que puso S.E. para que anduviese, al paso que pedian las instancias de su fervor, fué nombrar en el ingreso de su gobierno por superintendente y comisario de ella a D. Fernando Altamirano, caballero amabilísimo de extraordinaria virtud y singular prudencia, en quien verdaderamente concurrían las atenciones de cristiano con las observaciones de político.

Había sondeado el Exmo. sus talentos, y esplorado sus prendas la grande 
capacidad del Sr. conde de Alva en diferentes ocasiones, y especialmente en el ministerio de su mayordomo, reconociendo que no le enfermaban de ambicioso los favores, ni avaro el manejo de los tesoros, y así le vió llanamente todos los pertenecientes a la fábrica, en cuya administración procedía tan escrupuloso, que necesitando algunas veces de cantidades muy cortas para el sustento de su noble y dilatada familia, recurría al empréstito del amigo, por no tocar en el dinero de la obra, teniendo con que satisfacerlo cuando llegase el tiempo de distribuirlo, porque como destinado ál edificio del templo, le miraba como consagrado, pareciendo a su religión, que le profanaría en otros usos, y a su misma entereza, que con el más leve resguardo, y asegurando suplemento mancharía su fidelidad.

Ocioso habrá sido este encomio a los que le conocieron, pero tan debido a los que no le trataron, que si le omitiera en tan oportuna ocasión, acusaran dignamente de negligente, y aun de injusta a la pluma; porque cuando las alabanzas son debidas, las retiene con injusticia el silencio, y aun las usurpa a la utilidad común, escondiendo a la imitación los incentivos del ejemplo. Estuvo al cuidado de D. Fernando Altamirano la obra desde el año de 51 hasta el de 64 en que murió, con la intervención de su vigilancia; intentó S.E. empezar por lo más arduo, disponiendo se diese principio a la fábrica de las bóvedas mayores de la nave principal, para lo cual se corrió desde la capilla de los Reyes, hasta las columnas del crucero una imposta de cantería por ambos lados, conforme en la labor, e igual en el vueli, y correspondiente en la altura a los segundos chapiteles de las columnas, que componiéndose estas de cuatro medias muestras, las tres primeras exteriores están capiteladas para el cimiento de los arcos procesionales, y la media muestra interior seguidas las estrías, se continúan ambas en eminencia, y en la proporcionada tienen segundos chapitel donde se mueve los arcos de las bóvedas mayores. Labrada esta imposta, se fueron labrando sobre ellas seis formas que corresponden a las tres bóvedas primeras de la nave mayor, tres por cada lado, levantántandose estas formas hasta quedar acabados los cerramientos de diez y ocho ventanas que le corresponden, y en estado ya de echar las claves a los semicírculos que las ciñen. A la misma altura quedó tambien volado el arco toral inmediato al cimborrio, para cuya cimbría, como tambien para formar las de las bóvedas, y levantar gruas proporcionadas, se derribó primero el zaquizamí de madera, que en este espacio se había puesto el año 45, empezándose tambien a fabricar la torre sobre la capilla del Sagrario. Labróse el banco en que se funda, y se levantó el primer cuerpo hasta los primeros campaniles; obras todas, que si la atención del trabajo, el número de obreros, y la estimulación de S.E. no hubiera preocupado el tiempo que pedían, no pudieran haber cabido en el breve espacio de poco más de dos años.

En 15 de Agosto de 653 entró en México el Exmo. Sr. D. Francisco Fernández de la Cueva, octavo duque de Alburquerque de la Orden de Santiago; y aunque todas las partes de su gobierno, siempre plausibles, le merecieron estimaciones, generailmente le negació los afectos de todos el conato con que aplicó todas sus eficacias a la fábrica del templo. No aspiró la piedad de sus intentos a proseguirla sino a acabarla; y aunque no cupo la ejecución en el tiempo, venció al tiempo en lo que hizo; díganlo los progresos de la fábrica que como obra, lo dirán mejor que la mejor elocuencia, porque no hay más elocuente recomendación de las obras, que las obras . A la casi cotidiana personal asistencia de $\mathrm{S}_{\text {. }}$, que 
todas las más tardes pasaba del palacio a la iglesia, y a la influencia de su liberalidad, que señalando tareas a los obreros los provocaba al cumplimiento con ofertas y particulares premios, que a expensas propias distribuía despues su magnificencia, consiguió tantos aumentos la obra, que siendo en la realidad experiencia a los ojos, parecerá en esta relación encarecimiento al oido. En su tiempo se perfeccionaron las seis formas que dejó casi en clave al arco toral inmediato al cimborrio, levan tóse en él todos los arcos inmediatos, y se labraron las tres bóvedas primeras de la nave mayor. Levantáronse por ambas partes los extremos del crucero desde la primera imposta, siguiendo sobre ella el primer orden de las ventanas, y asentando sobre la segunda las formas de las claraboyas o ventanas circulares en sus medios, y sobre cuatro arcos, los unos estriados, y los otros áticos, correspondencia a las cuatro bóvedas. Se hicieron las columnas del crucero que son también dichas bóvedas mayores y elevadas a la altura antecedente. Hiciéronse desde sus formas las bóvedas procesionales inmediatas al crucero, y las bóvedas de siete capillas, que faltaban que cubrir en toda la iglesia. En el segundo cuadro de la nave principal se hizo el presbiterio, o banco del altar mayor, murado de cantería, y coronado por las tres partes de baluartes de fierro. Levantáronse los muros del coro, que ciñen dos cuadros de la misma nave con zócalos, ángulos y cornisas de cantería Sobre éstas se siguió por lados y cabecera una tribuna volada de cedro y tapinceran, madera preciosísima en este reino, que sobre un leonado artificioso varió de negro artificiosamente la naturaleza misma. El cuadro del cimborrio se techó de madera en forma de tijera; pero con tal fortaleza, que cuandollegase el tiempo de edificarla, pudiese sostener su cimbria, mirando a no embarazar el uso de la iglesia en el tiempo de sus edificaciones, y con la misma prevención se cubrió a techo tendido, desde los chapiteles de las columnas el demás espacio de la iglesia que restaba de acabar, prosiguiéndose el edificio de la torre hasta perfeccionar el primer cuerpo, que cierra con una bóveda de mucha eminencia. Para ocupar todos sus claros condujo S.E. de diferentes partes doce campanas las más preciosas y sonadas de todo el reino, que con otras ocho que tenía la iglesia, llenaron los veinte campaniles del primer cuerpo, con cuya armonía elocuente al viento dice a mucha distancia las grandezas de México, mejor que la torre del laberinto de Porcena, rey de Etruria, resonaba las de Italia.

Todo lo referido se obró desde el año de 53 hasta el de 60; pero antes, estando la Iglesia, que toda la evidencia de los ojos apenas bastaba a persuadir sus aumentos, porque ya los había aprendido la desconfianza imposibles, determinó S.E. se celebrase solemnemente su dedicación, como se hizo en 2 de Febrero de 656, día tan lleno en lo festivo, que pudieran quedar exhaustas las esperanzas de otro mayor, si en materias de religión fuera capaz de desmayar la piadosísima magnificencia de Mếxico. Todo el caudal sí de los ventajosos ingenios de sus hijos quedó sin alientos de aspirar a competir con el sermón que en aquella ocasión predicó y dió en las prensas a la admiración el doctor y maestro D. Estéban Beltran de Alzate, canónigo magistral, y hoy maestro escuela de esta santa iglesia, catedrático de primera de sagrada escritura.

En 16 de Septiembre de mil seiscientos sesenta sucedió en el gobierno el Exmo. Sr. D. Juan de Leiva y de la Cerda, marqués de Leiva, conde de Baños: siendo otro el gobernador, no fué otro el desvelo en la diligente presecución, pues se siguió tan a un paso, o se prosiguió tan a un vuelo, que no pareció 
distinto, sino uno mismo el cuidado, grande motivo a los elogios de S.E., si no se niega a la verdad la razón. Así lo es el vigilantísimo cuidado del $\mathrm{Sr}$. conde de Baños en la continuación de la fábrica. En su tiempo se hicieron con los arcos y las formas que les corresponden, dos bóvedas de la nave mayor, la inmediata al crucero, y la que sigue, que es la primera sobre el coro, cuatro de las naves procesionales, y se labró sobre las pechinas el cimborrio, obra la más ardua de todo el templo, en que se compitieron lo maquinoso y lo perfecto; y excediendo a la altura de sus claves las eminencias del arte, quedó mayor que su grandeza el primor de su arquitectura: cerróse el círculo de antería en que se mueve un fanal de la cúpula, en 10 de Julio de 1664. En 29 del mismo mes y año sucedió en el gobierno el Ilmo. y Exmo. Sr. D. Diego de Osorio, Escobar y Llamas, Obispo de la Puebla, y sucediéndola también en el celoso fomento, la dió todos los fomentos que cupieron en la brevedad del tiempo que gobernó.

\section{La Voz de México.}

22 de octubre de 1881, p. 2.

\section{DOCUMENTO No. 6}

\section{LA CATEDRAL DE MÉXICO}

En 15 de Octubre de 1664 recibió en esta imperial ciudad al Exmo. Sr. D. Antonio Sebastián de Toledo, marqués de Manzanera del órden de Alcántara, comendador de Puerto Llano en la de Calatrava. En el celo de S. E. en su religión, en su prontitud a la ejecución del gusto real sobraron motivos para proseguirla. Siguióla, puso su cuidado hasta conseguir enteramente la última perfección de todo lo interior del templo, labráronse a la influencia de su solicitud desde el principio, las formas y movimientos de los arcos, los tres últimos arcos de la nave mayor, y las cuatro procesionales por dos bandas inmediatas a la fachada principal que mira al Mediodía, cuyos muros se levantaron con tres claraboyas en sus medios hasta cerrar en la eminencia de los arcos. Reparóse el muro anterior de la capilla de San Miguel que había hecho algún sentimiento; y por ser angular, y en la que ha de levantarse la segunda torre, fué de grandísima importancia su reparo. Había S. E. escrito a $S$. M. la reina, que Dios guarde, el año pasado de 667 , que dentro de él se podía esperar perfectamente acabado todo lo interior del templo, si no hubiera consultado primero los esmeros de su cuidado, que la dificultad de lo prometido aun con la limitación de lo esperado, casi no se pudiera excusar de temeridad la promesa; pero siendo su misma solicitud fiadora del cumplimiento, sobró término a la palabra, pues estuvo desempeñada por los principios de Diciembre del mismo año, tiempo en que venía caminando una real cédula de 4 de Octubre, donde la religiosísima atención de $\mathrm{S}$. $\mathrm{M}$. dándole las gracias por la noticia, le reconvenía a la ejecución, por estas palabras que refiero, porque la energía de su contesto sea en lo futuro testimonio de su piedad austriaca. Referios en otras de 11 y 17 de Abril el buen estado en que se halla la fábrica material de la Santa Iglesia Metropolitana de esa ciudad de México y que se puede esperar dentro de este 
año la total y perfecta conclusión de la obra en todo lo interior del templo, y la buena economía con que habeis procurado se disponga. $\mathrm{Y}$ holgado con estas noticias, espero de vuestro cuidado y atención, adelantareis esta obra de manera que con brevedad se vea en toda perfección. En estas últimas palabras, no contento el católico celo de S. M. con la conclusión de lo anterior, encarga la esterior y total, ordenando que sea con brevedad toda su perfección; en cuya obediencia prosigue hoy S. M. levantando las dos columnas o estribos esteriores de la fachada, correspondientes a las tres naves entre que se han de edificar las tres portadas principales con ánimo de principiarlas luego: supuesto este ánimo, y la confianza de su cuidado, merecida a pruebas de experiencia, espera muy en breve el término de lo que aun aguarda el principio.

"Desde el principio de la fábrica, que como se ha dicho, fué el año de 1563, hasta Diciembre del pasado de 667, en que acabado todo lo interior, se celebró su deseada y última dedicación, ajustada la cuenta de su costo por la situación fija que ha tenido cada año, que han sido 18,500 pesos, añadiendo 13,000 que ha suplido más la real casa de la fábrica, ha costado 1'752,000 pesos.

"Aunque en lo antecedente se ha dado por partes alguna luz al conocimiento de la grandeza del todo de esta iglesia, no tanta que baste para hacer el concepto que debe corresponder a su fábrica; y así, referiré la descripción que dije de ella en otra parte, por pedirla aquí esencialmente el argumento de este escrito.

"La forma de su arquitectura es de órden dórico, la materia de sus columnas, bases, chapiteles, cornisas, frisos, estribos, arbotantes y guarniciones es de cantería, y lo restante de sus muros y macizos de sus paredes, de una especie de piedra roja, que siendo muy porosa y lijera, con todas las bocas de sus poros arguye claramente la singular providencia con que la crió Dios en las cercanías de México, proporcionándola a su terreno, y previniéndola a la constancia de sus edificios. Tiene de longitud el templo, por su planta o pavimento, que corre del Mediodía al Septentrión, 393 piés, que componen 64 varas, excluyendo en estas medidas los anchos de las paredes. Divídese su planta en cinco partes, que son: la nave mayor, las dos procesionales y las capillas, que por los dos lados ciñen y terminan la fábrica: la nave máyor tiene de diámetro de columna, 53 piés, las procesionales 33 y lo mismo las capillas. Tiene siete portadas, dos al Septentrión a los lados de las capilla de los Reyes, que corresponden a las naves procesionales, y están enteramente acabadas; dos a los extremos del crucero, que miran al $\mathbf{O}$. y al $\mathbf{P}$, cuya hermosa arquitectura se compone de cuatro medias columnas estriadas, con sus nichos intermedios, sobre sus chapiteles; volada una primorosa cornisa, recibe otras cuatro menores que están hoy más de la mitad, $y$ han de guarnecer las tres ventanas, las dos colaterales cuadradas, y la de en medio con cerramiento raído, sobre la cual está otra circular: las otras tres portadas (que como diferentes, aunque desean hoy su principio esperan breve su fin), son las de la fachada principal que corresponde a la plaza mayor y mira al Mediodía. El todo de la iglesia, hace forma piramidal, disminuyéndose proporcionalmente sus alturas desde la nave mayor hasta las capillas. De las ventanas, que son 164 , tres en cada forma, las colaterales cierran en círculo, y las de en medio son obras de córtes, guarnecidas de molduras, con cerramientos de concha y derrames esteriores e interiores, así participan a lo interior del templo grande claridad, recibiendo enteramente y sin embarazo la luz. La nave mayor y las dos procesionales, se forman sobre veinte antas o columnas, diez 
por cada banda, que desde el principio de la base al chapitel, tienen 54 piés, y de circunferencia 14; compónese cada una, de cuatro medias muestras estriadas, con sus traspilares correspondientes a las muestras estriadas de los muros y divisiones de las capillas. La cubierta es de cincuenta y una bóvedas, que asientan sobre setenta y cuatro arcos, y cincuenta y una formas, las bóvedas de la nave mayor y las de los cruceros, son de cañón de lunetas, cuyos perfiles, guarnecidos con medias molduras, suben a recibir los recuadros que se comparten en el espacio del cañón, en cuyo centro se forma un cuadro perfecto, en que asienta un escudo de armas reales de Castilla y León de medio relieve, dorado y orlado con la cadena del toison. A las esquinas del cuadro corresponden cuatro florones: en otros dos se terminan los ángulos de las lunetas. La capilla de los Reyes es de forma exágona, y su cubierta, de dos bóvedas, divididas con arcos que se forman sobre las columnas áticas a que corresponden los arcos; la bóveda que está sobre el altar es esquifada, compuesta de tres paños guarnecidas de moldura, que suben desde los principios de su nacimiento hasta la clave donde cierran, con un florón de hermoso dorado y bello relieve y follaje; sobre las cuatro antas o columnas del medio del crucero, se levantan los cuatro arcos torales que reciben la cúpula o cimborrio; entre ellos hay de diámetro 50 piés geométricos, a que corresponden 212 de circunferencia.

Entre los cuatro ángulos donde se mueven los arcos, se levantan cuatro pechinas, que siguiendo el balance y movimiento de los arcos, cierran en la misma altura de sus claves en triángulos equiláteros, haciendo en su eminencia figura ochavada perfecta, la cual se corona o perfecciona con las molduras de un arquitrabe y cornisa, en cuyo friso están repartidos los triglifos y metopas que pide para la más cabal hermosura y perfección de semejantes edificios el arte: tienen de altura 12 piés, el arquitrabe, friso y cornisa; en ésta se mueve un banco de ocho paños en que están otras tantas ventanas, guarnecidas con pilares, basas, chapiteles, que resaltados y seguidos guarnecen y ciñen toda la circunferencia del ochavo: tiene este banco de altura, desde la cornisa en que se mueve hasta el chapitel que le corona, 27 piés. El cerramiento de la cúpula es terciado, y sigue la figura del banco en ocho paños iguales, guarnecidos de molduras que suben hasta la clave, la cual forma un círculo abierto de 9 piés de diámetro, sobre que carga, o se forma la linternilla o fanal en que remata el cimborrio, la cual es también ochavada, con los cuatro lienzos macizos, y cuatro ventanas en los otros. Desde la clave de la cúpula al pavimento del templo, hay 184 piés, sobre que sube otros $44 \mathrm{el}$ fanal; las bóvedas de las naves procesionales son vaídas, y desde su nacimiento a su centro suben ocho fajas de relieve, que cerrando en círculo, guarnecen con él un escudo de armas reales, dando lugar a cuatro florones en correspondencia al adorno de las bóvedas mayores. Las de las capillas son de crucería o alacería de diferentes repartimientos, pero correspondidos con igualdad de uno y otro lado, a las capillas, se sigue por la parte del Septentrión, al lado de la epístola la sacristía y al del Evangelio en correspondencia la sala capitular, cubierta cada una con bóvedas de lazos: sus puertas, que salen a las naves procesionales, son de igual perfectísima arquitectura. Después de la capilla de los Reyes, quedando desembarazado el espacio de una bóveda para el tránsito de las procesiones, entre las cuatro columnas que siguen, se levanta el presbiterio, sobre un pedestal de cantería, que ciñe todo el cuadro, siguiendo las molduras de las basas y plintos, a cuyo pavimento se 
sube por nueve gradas; las siete seguidas con igual huella, $y$ las dos separadas, que forman mesas suficientes para la asistencia de ministros y acólitos. Desde la primera grada de la paena hasta la primera del coro, hay 138 piés de distancia, a que corresponden tres bóvedas mayores; una delante de las gradas, la del cimborrio enmedio, y otra delante del coro, en cuyo espacio se ponen los asientos del señor virrey, real audiencia, tribunales y ciudad.

El coro ocupa el espacio de dos bóvedas, su pavimento está en igual elevación con el del presbiterio; su reja y puerta son de cedro, y palabitres torneados de tapincerán, de que también es el antepecho del asiento anterior de los capitulares y las puertas y rejas de todas las capillas A la espalda del coro está el altar del Perdón; enfrente de la puerta principal de la fachada, y entre ella y el altar queda el espacio de dos bóvedas.

\section{La Voz de México}

Diario Político, religioso, científico y literario

25 de Octubre de 1881.

\section{DOCUMENTO No. 7}

\section{LA CATEDRAL DE MÉXICO}

La imagen de Nuestra Señora de la Asunción, (misterio titular de esta iglesia), es de oro, como también la peana y cuatro ángeles que asisten reverentemente obsequioso a tanto propiciatorio; pesa 139 marcos, que hacen 6,984 castellanos; y aunque sobre tan noble materia añadió preciosidad la variedad de piedras, que brillantes estrellas resplandeciendo en mejor cielo, pudieran dar envidia a los astros, si cupiera pasión en los insensible; con todo, vence a la materia la forma, siendo tan vivo el movimiento de la planta, tan airoso el impulso del vuelo y tan afectuosamente elevado el rostro, que parece repite al original los movimientos, y agilitándole el arte, sin obstarle el peso, sube también el retrato: tiene también otra imagen de plata, que es de la Concepción, de más de una vara, y pesa 138 marcos; está en la capilla propia de su advocación, asignada al gremio de la platería de esta ciudad, cuyos artifices costearon y colocaron esta imagen en la iglesia vieja el año de 618; y viendo en ella todas las inteligencias del arte, la sacaron tan al deseo de su devoción, como si la hubieran fundido en la forja de sus afectos. La primera capilla del lado del Evangelio, correspondiente al presbiterio, está dedicada al culto de una primorosa imagen de talla, del gloriosísimo protomártir de las Indias; San Felipe de Jesús, natural de esta ciudad, hijo de la profesión religiosa de la sagrada descalcés de San Francisco, cuyo hábito recibió en la provincia de San Gregorio de las Islas Filipinas, donde como Moisés para la zarza, se descalzó para la Cruz; y siendo su martirio, victoria de su nombre, fue, como decía San Gerónimo, nueva corona de Jesús su martirio: siguiéndole en la muerte como en el nombre, bebió crucificado en el Japón por las bocas de tres heridas, en que sirviendo de lenguas los fierros de tres lanzas, publican al mundo en su constancia, el honor más glorioso de esta noble ciudad, la cual celebró su canonización en 5 de Febrero del año de 1629 , con la extraordinaria y rara circunstancia de asistir a ella su madre, 
Antonia Martínez, natural de Salamanca en los reinos de Castilla, a quien apresuró la muerte el goza de tanta dicha, consiguiendo la de poder decir en su testamento, que otorgó el 27 del mismo mes y año, estas palabras ni dignas de omitir, ni fáciles de leer sin que perturben el uso de la vista, las lágrimas en que ejecuta a la piedad el nunca visto contesto de esta cláusula "Item declaro: que fuí casada velada, según orden de nuestra Santa Iglesia con el dicho Alonso de las Casas. Y durante nuestro matrimonio hubimos y procreamos por nuestros hijos legítimos de legítimo matrimonio primeramente al gloriosísimo santo mártir', San Felipe de Jesús y de las Casas, mártir del Japón, del orden de Nuestro Padre San Francisco, criollo de esta ciudad de México, descalzo, cuya festividad se ha estado celebrando estos días en dicha ciudad de México y le han nombrado por patrón de ella, \&c."

Si fuera de la principal veneración que se debe a las imágenes por serlo, también tienen otro linaje de estimación, o por la antigüedad o por la soberanía de la mano que las dona al adorno de los templos, no falta esta circunstancia a las grandezas de éste, pues en la primera capilla del lado de la epistola, cuyas paredes visten excelentísimos lienzos de la Pasión, venera compasiva la piedad de la devotísima imagen de un Crucifijo de talla, de estatura entera, que remitió a esta iglesia el señor emperador Carlos $\mathrm{V}$. Con otra imagen también de talla que se guarda hoy con toda docencia en la sala capitular. En la segunda capilla del lado del Evangelio, que por cédula particular confirmatoria del rey nuestro señor D. Felipe IV, pertenece a la ilustre archicofradía del Santísimo Sacramento y caridad, fundada en esta ciudad en 16 de Junio de 1538. Favorecida de la Santa Sede Apostólica con innumerables gracias e incorporada a la Santa Lateranense de Roma, esta otra admirable imagen de un Crucifijo de bronce, que envió a la misma cofradía la santidad de Pío V. En ésta, y las demás capillas (que todas son catorce), para aumento de la hermosura, se corresponden con igualdad el adorno; ya en los retablos, que ciñendo las ventanas con pilastras y cornisas de relieve doradas, siguen el orden de su arquitectura, hasta cerrar el círculo de la bóveda: ya en la riqueza de los frontales que, según la diferencia de los días, varían en los colores la religiosa gala de los altares, siendo muchos de plata de martillo, con láminas de medio relieve, repartidas de las frontaleras y caidas: ya en lo ponderoso de muchas lámparas cuyas continuas luces son permanentes llamas de los fervores del culto: ya en lo numeroso de los candeleros y blandones imperiales, en que sobra a cada capilla lo que basta a una iglesia. Y finalmente, están en todo lo demás tan correspondidas, que aun en el excederse se igualan, siendo cualquiera que se ve exceso de las otras que se han visto.

Si otra de las partes que constituyen el adorno de un templo, es el feliz. empleo de la plata y el oro en custodias, cálices y otra alhajas del ministerio de la iglesia, bien podemos decir gustosos, con el gran padre San Agustín, que también nosotros tenemos en ésta lo más precioso de los metales, consagrado a Dios en instrumento de su culto. La custodia en que se lleva al Santísimo Sacramento el día de Corpus, se compone de dos cuerpos, tan curiosamente labrados, que lo menos para su aprecio es pesar $\mathbf{5 0 0}$ marcos de plata, porque lo más es no tener precio lo primoroso de su hechura. Para este día tiene dos viriles que sirvan alternados, el uno de oro y ámbar, guarnecidos de esmeraldas y perlas, que pesa 904 castellanos. El otro mayor, y también de oro, con varias 
piedras preciosísimas, entre las cuales solo un zafiro está apreciado en 1,000 pesos, tiene una cruz de oro de 325 castellanos, admiración de los más peritos artífices en lo raro de su curiosidad, cuyo centro es custodia a una parte del Santo Lignum Crucis; sírvele de peana caja de finísimos corales, guarnecidos de plata, decente guarda de otras reliquias El cáliz y patena que se reserva para el depósito del Santísimo Sacramento es de oro, y pesa 643 castellanos, está variado con esmaltes blancos y azules que sirven de asiento a lo más precioso de las piedras, admitiendo únicamente en sus engastes, rubíes, esmeraldas y diamantes. Para la bendición solemne de la fuente bautismal, que se celebra los sábados santos, tiene una pila de plata que le donó el Ilmo. Sr. D. Juan Pérez de la Cerna, su Arzobispo. Baste decir, que solamente es un facistol, seis blandones imperiales del altar y cuatromayores de cirios, que se ponen en el plano del presbiterio, y los ciriales, que sirven al culto casi ordinario, pesan 1,057 márcos de plata. Esto es algo del adorno de la santa iglesia de México; el silencio de lo demás, cuidado del estudio, no tanto por no cansar con lo mucho, cuanto porque son desgraciadas las verdades que afirman grandezas de las Indias, y cuando de las otras partes creemos volúmenes muy crecidos, llegamos a temer si de este reino tildará la incredulidad renglones muy pequeños.

La Voz de México.

26 de octubre 1881 , p. 1. 